\title{
Forest Perception and Knowledge of Hikers and Mountain Bikers in Two Different Areas in Northwestern Switzerland
}

\author{
CLAUDIA HEER \\ HANS-PETER RUSTERHOLZ \\ BRUNO BAUR* \\ Department of Integrative Biology \\ Section of Conservation Biology \\ University of Basel \\ St. Johanns-Vorstadt 10, CH-4056 Basel, Switzerland
}

ABSTRACT / Recreational activities can have major impacts on vegetation and wildlife in frequently visited forests. We assessed forest perception and knowledge (state, functions, and species diversity) among hikers and mountain bikers in a frequently visited, seminatural suburban recreation forest (Muttenz) and in a more distantly situated, naturally grown excursion forest (Wasserfallen) in northwestern Switzerland. In all, 239 hikers and 126 mountain bikers were interviewed. Mountain bikers in both forests and hikers in the more intensely used recreation forest at Muttenz assessed the state of the forest less optimistically and showed a higher awareness of the negative impact of recreational activities on the flora and fauna than hikers at Wasserfallen. Furthermore, mountain bikers seemed aware of the social conflicts caused by their activity, since they appreciated neutral or positive encounters with other forest visitors. In contrast, $57 \%$ of hikers at Muttenz reported on negative experiences with other forest visitors, particularly with mountain bikers. In general, the interviewees' ecological and biological forest knowledge (forest type and function, species diversity) was rather high. A large proportion was aware of the pros and cons of different forest conditions for plants and animals, and could name or recognize at least some plant and/or animal species typical for the visited forest. The forest knowledge was neither influenced by the type of recreational activity carried out nor by any aspect of forest visit behavior (frequency and duration of forest visits, means of transportation and travel distance to forest). However, the interviewees' forest knowledge was influenced by their age and educational level.
The significance of forests as natural spaces for recreation has continuously increased in recent decades, due to changes in life-style and working conditions (Volk 1992; Lamprecht and Stamm 1994). More leisure time and relatively higher incomes have generated a variety of outdoor activities carried out in forests and the open countryside nowadays. Mountain biking, for instance, has increased in some urban forests to the extent that it is now exceeding the traditional walking/ hiking. In addition, higher mobility has enlarged the area of intense recreational forest usage.

Besides the types of recreational forest activities, the frequency and duration of forest visits also have changed. Volk (1992) found for an urban forest in Germany higher frequencies of daily forest visits, as well as a longer mean duration of forest visits in 1988 compared to 1970 . In Switzerland, almost $60 \%$ of the pop-

KEY WORDS: Forest recreation; Forest visitor groups; Forest conditions; Recreation impact; Social conflicts; Visitor survey

Published online June 23, 2003.

*Author to whom correspondence should be addressed; email: bruno.baur@unibas.ch ulation visit a forest at least once a week during summer and about $40 \%$ during winter (BUWAL 1999).

In urban areas, forests are usually the only natural spaces available for outdoor recreation for a comparatively large number of people (Jacsman 1998). The intense recreational use has significant impacts on vegetation and wildlife (Baur 1999). For instance, trampling damages the ground vegetation and compacts the soil. This leads to a reduction of both plant cover and establishment of tree seedlings and in some cases also to the local extinction of plant species (Baur 1999). Trampling additionally crushes leaf litter in small pieces, which are more easily blown away by wind. Besides reducing nutrient recycling, this leads to habitat loss for decomposing organisms. Furthermore, the use of woody debris for firewood at picnic sites reduces the habitat of xylobiontic insects.

Other consequences of the intense recreational use of forests are social conflicts and competition, particularly between forest visitors pursuing different kinds of activities. For instance, in a recreation forest in the United States (Michigan), one third of the visitors was bothered by other forest users, in particular by their actions and the way they behaved, but much less by the mere number of encounters (West 1982). Mechanized 
forms of recreation are often implicated in conflicts. In a suburban forest near Basel, Switzerland, where almost $50 \%$ of the visitors felt disturbed by other people or their behavior, careless mountain bikers were one of the major sources of complaint (Baur 1999; Kleiber 2001). In many cases, hikers expressed safety concerns due to irresponsibly riding mountain bikers (Moore 1994; Hoger and Chavez 1998). Similarly, 32\% of hikers, but only $6 \%$ of mountain bikers made a conflict attribution directed towards the other forest visitor group in a study conducted near Salt Lake City, Utah, USA (Ramthun 1995). As a consequence, forest management has to cope with a new challenging task, namely the simultaneous maintenance of different forest functions. Recreational use is becoming the most important function in suburban forests, while protective functions such as water retention and prevention of soil erosion should be ensured and a sustainable timber production maintained. Furthermore, the forest has to serve as habitat for plants and animals, many of which are endangered. Restrictive regulations of forest use could be a means to solve the conflicting interests in frequently visited areas. However, regulations are often ignored by forest visitors. Such ignorance could result from a lack of perception and knowledge of the prevailing forest conditions.

Martin and others (1989) found differences in the perception of resource conditions between forest users and forest managers. While forest managers were more sensitive to the presence of bare ground, forest visitors found tree damage and fire rings more objectionable. In a recreational area close to the river Rhine, more than $50 \%$ of the visitors perceived some form of environmental degradation (Baudepartement Kanton Aargau and Landratsamt Waldshut 1999). Local recreationists were more sensitive than holiday visitors. They perceived with a higher frequency litter and other forms of pollution (e.g., dog dirt) and more often made social complaints (e.g., about crowding). Several studies have shown that visitors' perception of resource damage or environmental degradation is positively correlated with the perception of crowding (Womble and others 1980; Bultena and others 1981; Ditton and others 1983). Similarly, in a frequently visited suburban forest in Switzerland (up to 120 visitors per hour), more than two thirds of the visitors interviewed believed that some recreational activities damage the forest (Baur 1999). Among them, $28 \%$ assumed that picnics and barbecues cause damage to the forest in the area of picnic sites, whereas $16 \%$ thought that mountain biking damages the forest. Moore (1994) and Hoger and Chavez (1998) also reported that hikers believe that mountain biking degrades the natural resource, e.g., by creating informal trails. In another study, bikers perceived themselves to be significantly less damaging than horse riders or motorized vehicle users, but significantly more damaging than walkers or hikers (Symmonds and Hammitt 2000).

It is important to understand the users of recreational forests as best as possible in order to adjust resource management to prevent or at least minimize possible conflicts and damage. The aim of the present study was to examine the perception and knowledge of the forest (including aspects of forestry, nature conservation, and social conflicts) in two forest visitor groups. As the type of forest (environment) might influence perception, two different forests were chosen for this study: a suburban forest (a typical recreation forest) and a more distantly situated forest in a mountainous region (a typical excursion forest). Hikers and mountain bikers, the most frequent forest visitor groups at both sites, were considered in this study. It seemed interesting to study and compare these two forest visitor groups since mountain bikers had caused conflicts with hikers in one of the forests in the recent past. Forest perception and knowledge were examined by direct interviews. The following questions were addressed: (1) Do forest perception and knowledge differ between hikers and mountain bikers? (2) Do forest perception and knowledge of hikers and mountain bikers visiting a suburban recreation forest differ from those of hikers and mountain bikers visiting a more distant, rural excursion forest? (3) Do forest perception and knowledge depend on demographic variables (sex, age, educational level, etc.) and/or on forest visit behavior (e.g., frequency or duration of forest visits)?

\section{Material and Methods}

\section{Study Sites}

Two forests with contrasting functions located in the northern Jura Mountains of Switzerland were chosen for this study. Winterhallen at Muttenz is situated $7 \mathrm{~km}$ $\mathrm{E}$ of Basel at an elevation of 280-350 $\mathrm{m}$ above sea level. The study area, about 2000 ha, is part of a more or less continuous forest system covering the Swiss Jura Mountains. It is a suburban beech forest with different types of dense stands belonging to the Galio odorati-Fagetum association (Burnand and Hasspacher 1999). Species richness of these stands varies from 13 to 52 plant species per $1000 \mathrm{~m}^{2}$. The study area is visited by numerous urban dwellers in the evening on weekdays. Recreational activities are diverse, including mountain biking, horse riding, hiking, and jogging, on an intensively managed trail system. There exist numerous areas for 
having picnics. As a result of the intense recreational use there is visible damage to ground vegetation, shrubs, and young trees, and the social conflicts between different groups of forest users seem pronounced.

The forest at Wasserfallen is situated $23 \mathrm{~km} \mathrm{SSE}$ of Basel at an elevation of 600-1000 m above sea level. Wasserfallen is a highly diverse landscape covered by natural forest and extensively managed meadows. The naturally grown forest consists of different types of spruce-fir-beech stands (Abieti-Fagetum) (Burnand and Hasspacher 1999). The number of plant species varies from 34 to 60 per $1000 \mathrm{~m}^{2}$. Wasserfallen is a typical excursion forest with an extensively managed hiking trail system and only few resting areas. It is accessible by cable car and is primarily chosen as a destination by hikers on weekends.

\section{Interview}

The interview consisted of 10 questions recording the interviewees' gender, age, level of education, membership in environmental organizations, as well as the forest visit behavior (group size, means and distance of journey to the forest, frequency and duration of forest visits). A further 13 partly subdivided issue questions examined the hikers' and mountain bikers' perception of the forest (positive and negative experiences), perception and knowledge of the forest state (good, intermediate, bad), naturalness and forest damage, knowledge and perception of forest functions, forest types and forest protection, and finally knowledge and perception of different forest tree species, as well as species diversity and its development in the forest (increase, decrease, no change). In general, issue questions were open-formulated to assess real perception and knowledge of hikers and mountain bikers (no choice of response categories). Responses were subsequently categorized for data analysis. All questions were asked orally, with the exception of a set of three statements on the naturalness of the forest with respect to its structure and tree composition (natural, seminatural, cultivated) that could be read by the interviewees. To examine hikers' and mountain bikers' species knowledge of different forest trees, they were presented dried, pressed leaves of beech (Fagus sylvatica), oak (Quercus robur), maple (Acer pseudoplatanus), and ash (Fraxinus excelsior). Furthermore, a set of four photographs (Figure 1A-D) with contrasting forest types was presented to the interviewees, to ask for the preferred forest type as well as to assess their knowledge of the benefit of different forest types for plants and animals.

\section{Survey}

The survey was carried out between 20 May and 28 October 2001. The questions were pretested and afterwards some improvements were made on formulation and/or response categories. Two frequently visited sites in each forest were used for the interviews. At Wasserfallen, one site was close to the edge of the forest; thus only hikers and mountain bikers leaving the forest were addressed. At the other site at Wasserfallen and at Muttenz in general, hikers and mountain bikers coming from either direction on a trail were asked for an interview. Approximately $75 \%$ of the persons addressed were willing to answer the questions. Hikers and mountain bikers did not differ in their willingness to participate in the interviews. To avoid pseudoreplication, only one person was interviewed in passing groups. Since the interviews were carried out by a single person, some hikers and mountain bikers were missed while interviewing someone else. On average, about every fifth of all passing hikers and mountain bikers could be interviewed per day (up to 22 interviews per day). Since horse riders and joggers very rarely came to the forest at Wasserfallen, these groups were not considered in the study. To increase the sample size of mountain bikers at Wasserfallen, we exclusively waited for members of this visitor group on some days towards the end of the survey period. A total of 65 hikers and 88 mountain bikers were interviewed at Muttenz, and 174 hikers and 38 mountain bikers at Wasserfallen.

\section{Data Analysis}

Five of the 365 interviews were excluded from the study due to incomplete demographic data $(N=360)$. For the analysis, "no answer/don't know" responses did not come to more than a few percent of all responses. However, almost $12 \%$ of the interviewees were not able to answer the questions regarding the state of the forest.

Log-linear models (SAS Version 6.02; procedure catmod) were used to analyze differences in demographic variables and aspects of forest visit behavior between forest visitor groups (hikers and mountain bikers), forests (Muttenz and Wasserfallen), and the interaction between studied visitor groups and forests. The same log-linear models were used to analyze differences in the interviewees' responses to the survey questions between visitor groups (hikers and mountain bikers), forests (Muttenz and Wasserfallen), and the interaction between the studied visitor groups and forests. The effects of demographic variables and different aspects of the interviewees' forest visit behavior on the responses to the interview questions were additionally tested using log-linear models. 
(A)

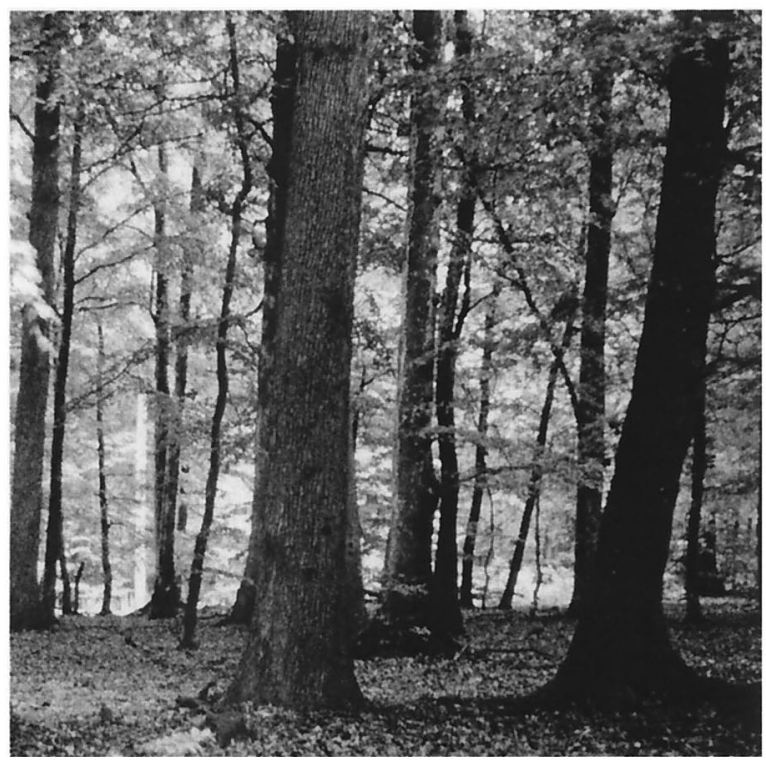

(C)

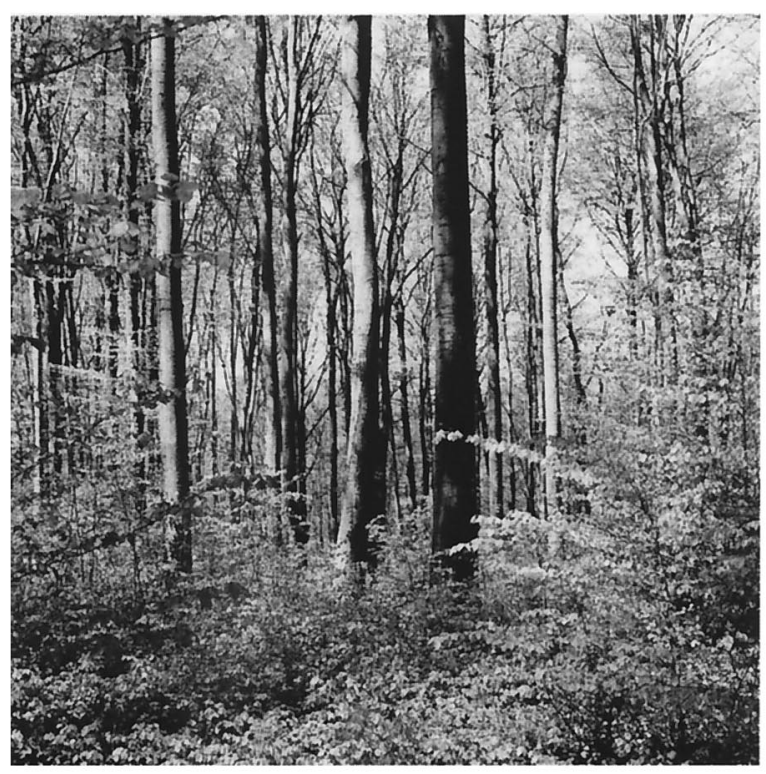

(B)

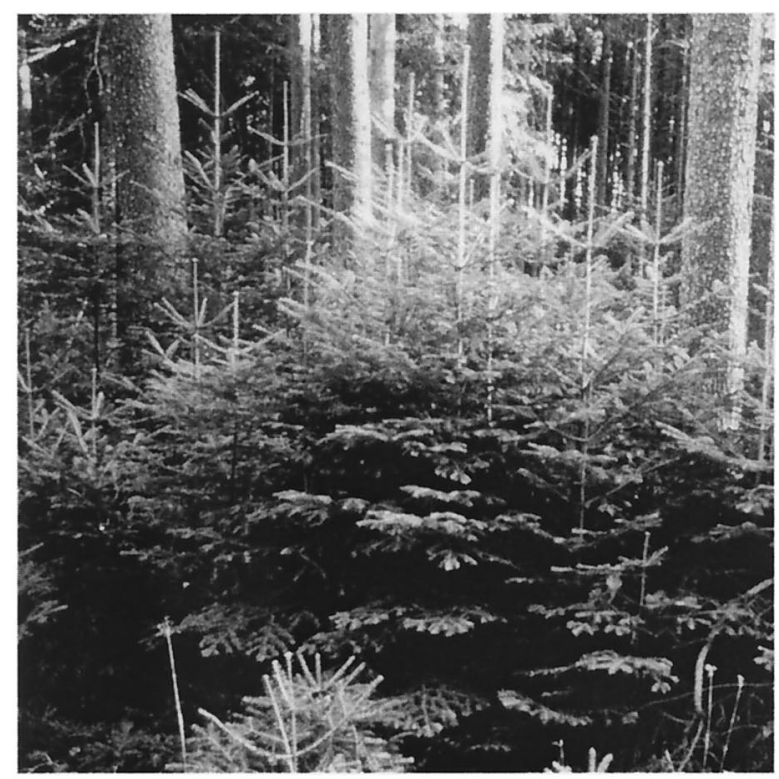

(D)

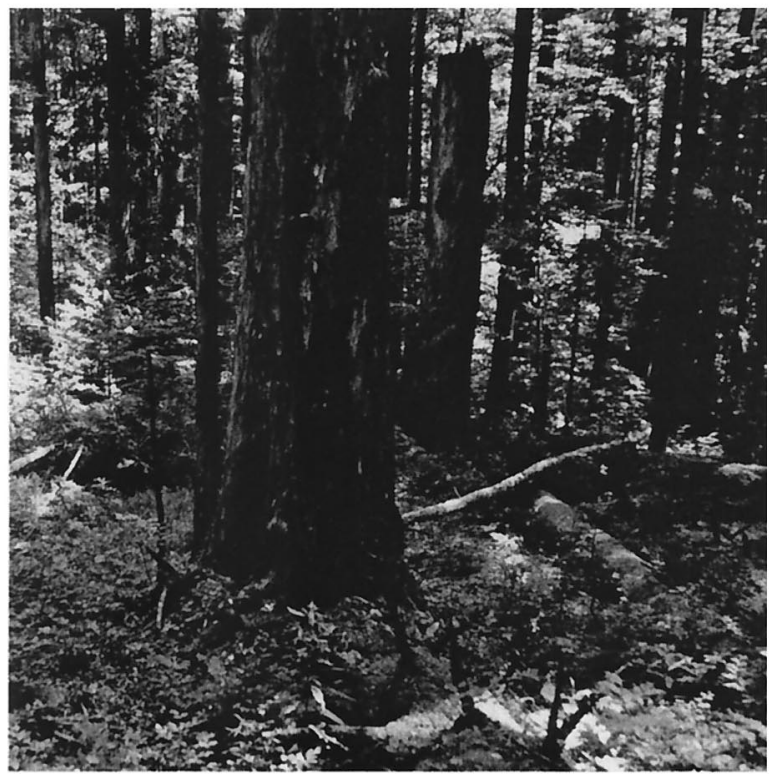

Figure 1. Photographs of different forest types shown to hikers and mountain bikers: highly degraded oak-beech forest (A); culture of conifers (B); naturally grown, highly structured beech forest (C); and primeval forest (D).

\section{Results}

Characteristics of Interviewed Hikers and Mountain Bikers

Demographic data and different aspects of forest visit behavior of the interviewed hikers and mountain bikers are presented in Table 1 . Hikers and mountain bikers differed in gender ratio. While the frequency of women and men was similar in hikers, mountain bikers were predominantly male $(87-89 \%)$. Furthermore, the age distribution differed between hikers and mountain bikers (Table 1). Generally, mountain bikers were younger than hikers. Seventy-seven percent of mountain bikers were younger than 45 years, but only $36 \%$ of 
Table 1. Demographic data and characteristics of interviewed hikers and mountain bikers ${ }^{a}$

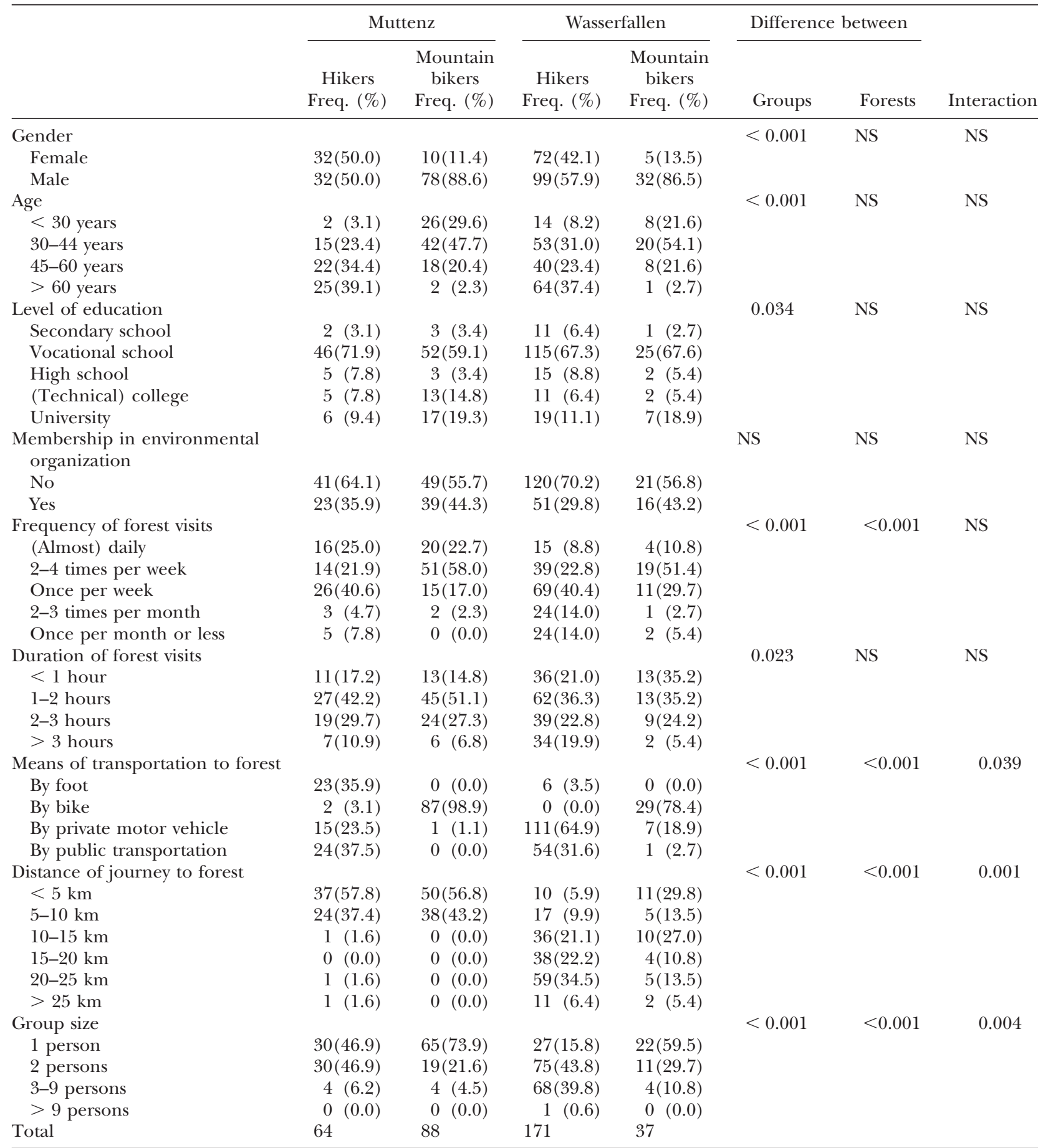

aThe interviews were conducted in two forests (Muttenz and Wasserfallen) in northwestern Switzerland. Log-linear models were used to analyze differences between the two visitor groups, the forests, and the interaction between the two visitor groups and forests $(d f=1$ in all cases). $P$ values are indicated for each comparison.

hikers. In contrast, $38 \%$ of hikers were older than 60 years, but only $2 \%$ of mountain bikers belonged to this age class. Although in both forest visitor groups about
$65 \%$ of the interviewees had a vocational school degree, a significant difference in the education of hikers and mountain bikers was found (Table 1). Thirty-one per- 
cent of the mountain bikers had a college or university degree, compared with $18 \%$ of hikers. In both studied visitor groups and forests, 30-44\% of the interviewees were members of an environmental organization.

Hikers and mountain bikers differed in the frequency of their forest visits (Table 1). A larger proportion of mountain bikers than hikers visited the forest more than once per week. Furthermore, a difference in the frequency of forest visits was detected between Muttenz and Wasserfallen. Hikers and mountain bikers at Muttenz visited the forest more frequently than those at Wasserfallen.

Hikers and mountain bikers also differed in the duration of their forest visits (Table 1). A larger proportion of mountain bikers stayed for shorter periods (up to $2 \mathrm{hr}$ ) in the forest, whereas a higher percentage of hikers stayed $3 \mathrm{hr}$ or longer.

Hikers and mountain bikers differed in the means of transportation they used to reach the forest (Table 1). Furthermore, hikers and mountain bikers used different means of transportation to reach the forest at Muttenz and at Wasserfallen, and there was an interaction between the two visitor groups and forests examined. While at Wasserfallen $65 \%$ of hikers arrived with a private motor vehicle, at Muttenz only $24 \%$ of hikers used this means of transportation and another $36 \%$ came by foot (Table 1). At Muttenz, nearly all mountain bikers $(99 \%)$ arrived by bike, while at Wasserfallen, $19 \%$ of mountain bikers used a private motor vehicle to reach the forest.

Hikers and mountain bikers differed in the distance they traveled to reach the forest (Table 1). The travel distance of both hikers and mountain bikers also differed between Muttenz and Wasserfallen, which resulted in an interaction between the two visitor groups and forests examined. In general, the travel distances to the forest at Muttenz were shorter than at Wasserfallen, and mountain bikers traveled shorter distances than hikers (Table 1). At Muttenz, 95\% of hikers and all mountain bikers traveled less than $10 \mathrm{~km}$ to the forest. At Wasserfallen, $16 \%$ of hikers traveled less than $10 \mathrm{~km}$ to the forest and $78 \%$ between 10 and $25 \mathrm{~km}$, while $43 \%$ of mountain bikers traveled less than $10 \mathrm{~km}$ and $51 \%$ between 10 and $25 \mathrm{~km}$.

The size of the group in which hikers and mountain bikers visited the forest differed between the two visitor groups and forests, and there was an interaction between the visitor groups and forests examined (Table 1). Mountain bikers in general and hikers at Muttenz more frequently came as individuals or in pairs to the forest than hikers at Wasserfallen.

\section{Differences in Forest Perception and Knowledge}

When hikers and mountain bikers were asked what spontaneously crosses their mind when they hear the term "forest," $50 \%$ of the statements included some form of "recreational function" (recovery, relaxation, quietness, peace, freedom, fresh air, or recreational activities such as walking, hiking, mountain biking, horse riding). Another $41 \%$ of the statements concerned different aspects of nature (plants, trees, animals, green, etc.).

Sixty-six percent of the interviewees mentioned something that positively attracted their attention on the way through the forest (positive perceptions), but only $31 \%$ reported any negative perception or experience. Positive perceptions were significantly influenced by the interviewed visitors' gender $\left(\chi^{2}=9.09, d f=2, P\right.$ $=0.011)$. Seventy-five percent of the women, but only $62 \%$ of all men reported something that positively attracted their attention. Nearly $50 \%$ of the positive perceptions mentioned were "impressions," such as "beautiful weather/sunshine," "pleasant climate in the forest," or "silence." Hikers and mountain bikers differed in the kind of positive perceptions (Table 2). Figure 2A shows that "impressions" were more common among mountain bikers than hikers (especially at Wasserfallen). Furthermore, mountain bikers more frequently reported on positive experiences with "other forest visitors" than hikers (particularly at Muttenz). On the other hand, hikers mentioned "forest state" or "plants/trees" as positive perceptions with a higher frequency than mountain bikers.

Hikers and mountain bikers also differed in the kind of negative perception, and there was an interaction between the studied visitor groups and forests (Table 2). Of the hikers at Muttenz, $57 \%$ reported on negative experiences with "other forest visitors" (Figure 2B). In mountain bikers the corresponding figure was only $22 \%$. At Wasserfallen, negative perception of "other forest visitors" occurred less frequently among both groups of visitors. In that forest, "litter" or "motor vehicles" were more frequently mentioned as a negative perception.

In both visitor groups and forests, the majority of the interviewees considered the state of the visited forest as "good" ( $81 \%$ of hikers, $59 \%$ of mountain bikers). Nevertheless, hikers and mountain bikers differed in their assessment of the state of the forest (Table 2). Seventeen percent of hikers, but $36 \%$ of mountain bikers considered the state of the forest as "intermediate," and $2 \%$ of hikers and 5\% of mountain bikers as "bad." Furthermore, women generally assessed the forest state somewhat better than men $\operatorname{did}\left(\chi^{2}=7.25, d f=2, P=\right.$ $0.027)$. 
Table 2. Differences in forest perception and knowledge between hikers and mountain bikers in two forests ${ }^{a}$

\begin{tabular}{|c|c|c|c|c|c|c|}
\hline & \multicolumn{2}{|c|}{$\begin{array}{l}\text { Difference between } \\
\text { groups }\end{array}$} & \multicolumn{2}{|c|}{$\begin{array}{l}\text { Difference between } \\
\text { forests }\end{array}$} & \multicolumn{2}{|c|}{$\begin{array}{l}\text { Interaction group } \\
\times \text { forest }\end{array}$} \\
\hline & $x^{2}$ & $P$ & $x^{2}$ & $P$ & $x^{2}$ & $P$ \\
\hline \multicolumn{7}{|l|}{ Perception of forest } \\
\hline Positive perceptions (detailed) & 7.03 & 0.008 & 1.38 & NS & 1.00 & NS \\
\hline Negative perceptions (yes/no) & 0.32 & NS & 0.91 & NS & 9.69 & 0.002 \\
\hline Negative perceptions (detailed) & 4.24 & 0.039 & 3.30 & NS & 5.53 & 0.019 \\
\hline \multicolumn{7}{|l|}{ Perception and knowledge of forest state } \\
\hline Assessment of forest state & 10.81 & 0.001 & 0.76 & NS & 0.41 & NS \\
\hline Assessment of factor influencing forest state & 8.13 & 0.004 & 7.96 & 0.005 & 2.67 & NS \\
\hline Perception of forest damages (detailed) & 4.05 & 0.044 & 5.89 & 0.015 & 2.69 & NS \\
\hline Statements on naturalness & 14.18 & 0.001 & 8.37 & 0.015 & 0.60 & NS \\
\hline \multicolumn{7}{|l|}{ Knowledge and perception of forest functions } \\
\hline Forest types (benefit for nature) & 6.31 & 0.012 & 1.75 & NS & 0.19 & NS \\
\hline
\end{tabular}

${ }^{a}$ Log-linear models were used to analyze differences between the two visitor groups, the forests (Muttenz and Wasserfallen), and the interaction between the two visitor groups and forests $(d f=1$ in all cases).

(A)

\begin{tabular}{|llll|}
$\square$ & Other & $\square$ & Plants/trees \\
$\square$ & Impressions & Other forest visitors \\
$\square$ & Forest state & & \\
$\square$ & Animals & & \\
\hline
\end{tabular}

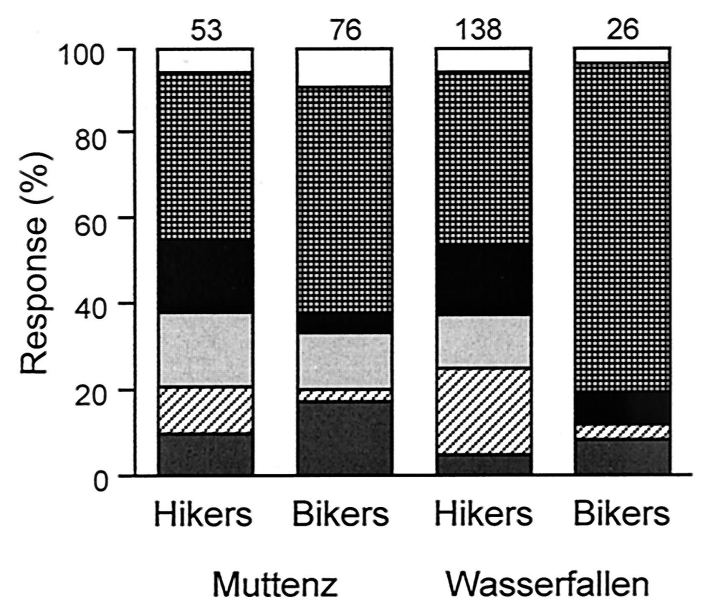

(B)

\begin{tabular}{|llll|}
$\square$ & Other & $\square$ & Paths/trails \\
$\square$ & Forestry & $\square$ & Litter \\
& Forest damages & $\square$ & Other forest visitors \\
& Motor vehicles & & \\
\hline
\end{tabular}

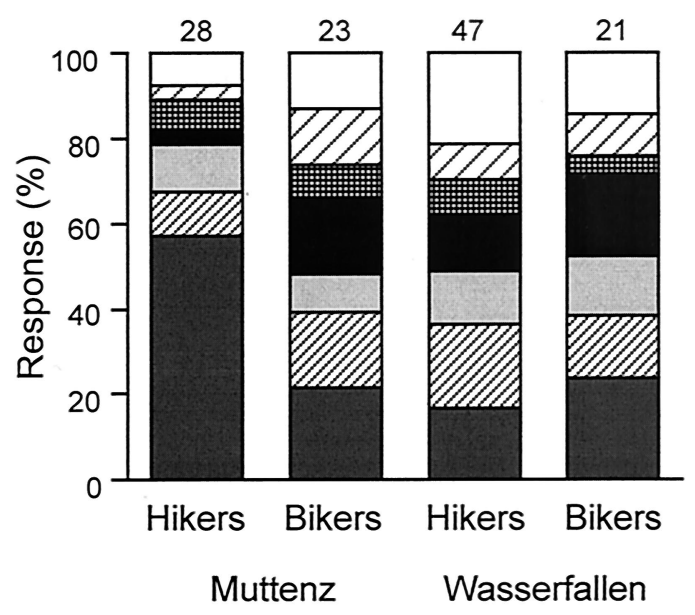

Figure 2. Positive (A) and negative (B) perceptions (\%) of hikers and mountain bikers in the forests of Muttenz and Wasserfallen. Numbers on top of columns indicate sample sizes, multiple responses were possible.

Significant differences in the response to the question of which factor may predominantly influence the state of the forest occurred between the two visitor groups and forests (Table 2). Hikers at Muttenz and both visitor groups at Wasserfallen mentioned "environmental pollution" with a higher frequency 
$(67-74 \%)$ than "recreational activities" $(9-15 \%)$ as the most important factor influencing the forest state. Contrary to this, mountain bikers at Muttenz considered "recreational activities" (38\%) and "environmental pollution" $(40 \%)$ as the main factors influencing the state of the forest. The interviewees relatively rarely mentioned "climate/global change" (7-12\%) and "forest management" $(6-11 \%)$ as factors influencing the forest state.

Of the interviewed hikers and mountain bikers, 85$95 \%$ had noticed some form of forest damage on the day of the interview or during a recent forest visit, irrespective of visitor group and forest. However, gen$\operatorname{der}\left(\chi^{2}=12.94, d f=2, P=0.002\right)$ and membership in an environmental organization $\left(\chi^{2}=7.02, d f=2, P=\right.$ $0.003)$ had an influence on the frequency at which forest damage was perceived. Women and members of environmental organizations more frequently reported on damage to the forest than men and those not members of environmental organizations. The visitor groups examined differed in the kind of forest damage perceived (Table 2). "Diseased/infested trees" and "dead/ fallen trees" were most frequently reported as forest damages, especially by hikers and at Wasserfallen (Figure 3A). On the other hand, mountain bikers at Muttenz reported "damage to forest floor/vegetation" with a higher frequency. Thus, different damages were perceived in different forests (Table 2). In addition, age influenced the perception of forest damage $\left(\chi^{2}=\right.$ $20.55, d f=6, P=0.002)$. "Litter" and "damage to forest floor/vegetation" were more often reported by younger interviewees ( $<30$ years), "diseased/infested trees" and "dead/fallen trees" by older ones ( $>45$ years) (Figure 3B).

Hikers and mountain bikers differed in the assessment of the naturalness of the forest structure and tree composition (Table 2). More hikers than mountain bikers considered both forests as "natural" (Figure 4A). Furthermore, the interviewees' assessment of the forest naturalness differed between Muttenz and Wasserfallen (Table 2). The proportion that assessed the forest as "natural" was more than twice as high among hikers at Wasserfallen compared to hikers at Muttenz or mountain bikers in both forests. On the other hand, a large number of mountain bikers at Muttenz considered the forest as "seminatural" or even as "cultivated." Furthermore, the assessment of naturalness was linked to the interviewees' age $\left(\chi^{2}=24.30, d f=6, P=0.001\right)$. Younger hikers and mountain bikers considered the forest as less natural than older ones (Figure 4B). Although statistical analysis revealed a significant influence of the travel distance to the forest on the inter- viewees' assessment of forest naturalness $\left(\chi^{2}=22.41, d f\right.$ $=10, P=0.013)$, no distinct pattern could be detected.

"Air/oxygen production" (33\%, all data combined) and "recreation" $(23 \%)$ were the forest functions most frequently mentioned in both visitor groups and forests (Table 3). Of the photographs presented showing four different types of forests (Figure 1A-D), $45 \%$ of the interviewees preferred the naturally grown "primeval forest" for their recreational activity (Figure 5A). Hikers and mountain bikers did not differ in their preference. Similarly, the same forest types were preferred in the two forests. The level of education, however, had a significant influence on the preferred forest type $\left(\chi^{2}=\right.$ $18.90, d f=8, P=0.015)$. While $51 \%$ of higher educated hikers and mountain bikers (college or university degree) stated a preference for "primeval forest" for their recreational activity, only $41 \%$ of those with a lower level of education (secondary or vocational school degree) chose this forest type. In contrast, a higher percentage of the latter preferred the "highly degraded oak-beech forest" (28\% compared to $16 \%$ among higher educated interviewees).

When the interviewees had to assess which of the four presented forest types was the most suitable habitat for many plants and animals, a majority chose the naturally grown "primeval forest." However, hikers and mountain bikers differed in their assessment (Table 2). Compared to hikers, mountain bikers selected the "primeval forest" with a higher frequency, and less often the "naturally grown, highly structured beech forest" (Figure 5B). The "highly degraded oak-beech forest" was hardly ever chosen as the best habitat for plants and animals. The interviewees' age $\left(\chi^{2}=16.02, d f=6, P=\right.$ $0.014)$ and frequency of forest visits $\left(\chi^{2}=18.52, d f=8\right.$, $P=0.018$ ) had significant influences on the assessment of forest types as ideal habitats for plants and animals. However, the only obvious trend was a relatively high percentage of older interviewees ( $>60$ years) judging the "highly degraded oak-beech forest" as the best habitat for plants and animals.

The most frequently stated reasons for protecting a part of a forest were "protection of animals," "preservation of plants (forest floor)," and "undisturbed development" (Table 4), but no differences between the two visitor groups or forests examined were found. However, female and male interviewees differed in their responses $\left(\chi^{2}=7.19, d f=2, P=0.028\right)$. Women more often stated "protection of animals" and "preservation of plants (forest floor)," while men more frequently mentioned "undisturbed development" and "scientific experiment."

No differences in knowledge and perception of biodiversity were found between the two visitor groups 
(A)

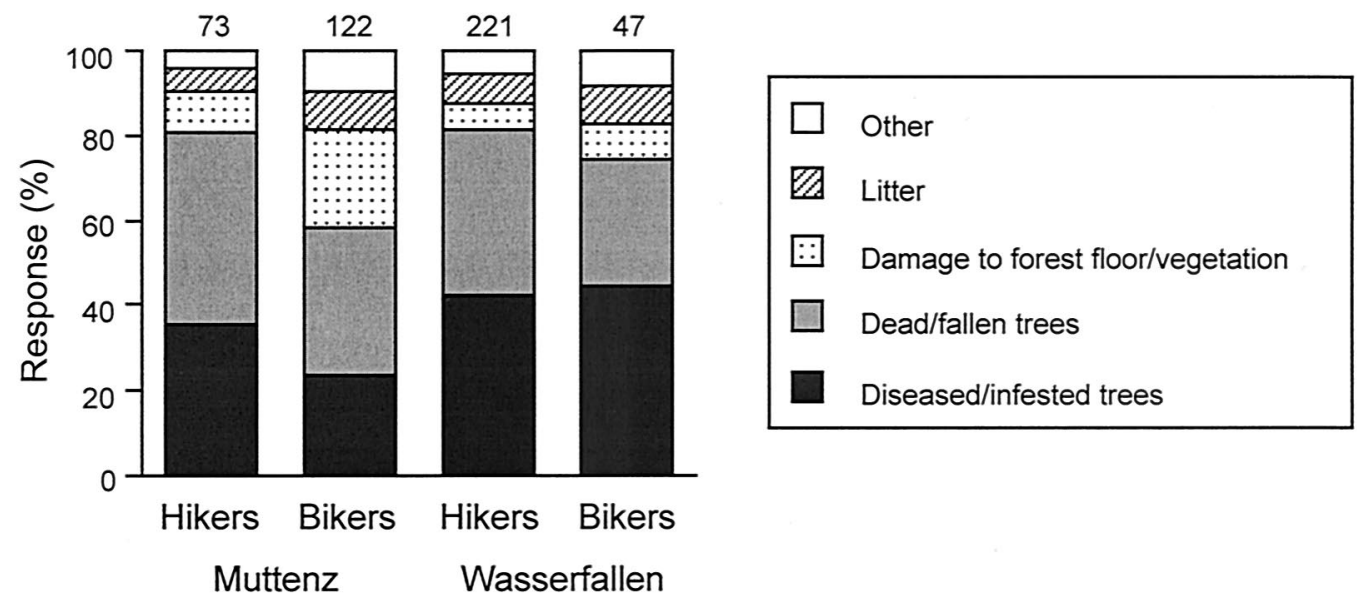

(B)

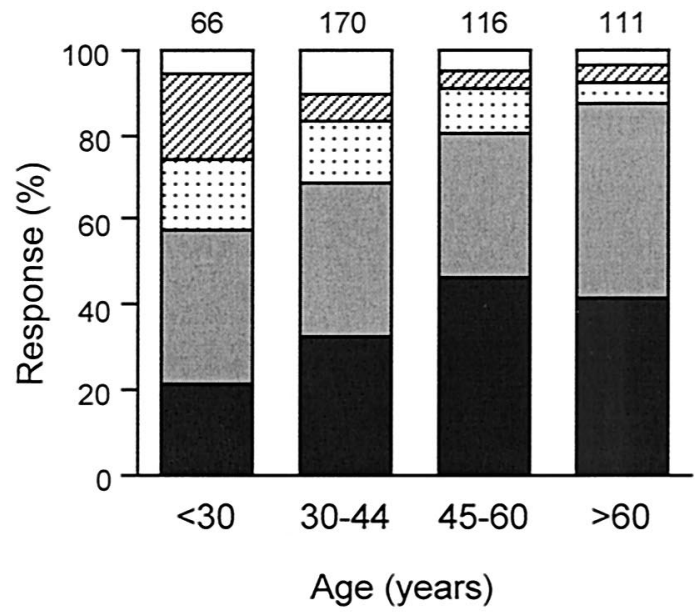

Figure 3. Perception (\%) of different kinds of forest damage (A) by hikers and mountain bikers in the two forests, Muttenz and Wasserfallen, and influence of interviewees' age on the perception of different kinds of forest damage (B). In (B)

or forests examined (Table 2). However, the responses were affected by interviewees' demographic parameters. Ninety-four percent of the interviewees had heard of "Artenvielfalt" (= species richness) before. Contrary to this, only $25 \%$ were familiar with the term "Biodiversität" (= biodiversity), but this proportion increased with increasing level of education from $6 \%$ among secondary school graduates up to $63 \%$ among those with a university degree $\left(\chi^{2}=28.79, d f=8, P<0.001\right)$. Furthermore, more members of environmental organizations were familiar with the term Biodiversität than data from both visitor groups and forests are combined. Numbers on top of columns indicate sample sizes, multiple responses were possible.

nonmembers $\left(34 \%\right.$ vs $19 \% ; \chi^{2}=8.79, d f=2, P=$ $0.012)$.

Seventy-three percent of the interviewees believed that the diversity of plants and animals had decreased in the visited forest in the past decades. Eighteen percent thought that species diversity had remained the same, while $9 \%$ presumed that it had increased during this period. The most frequently stated reasons for a presumed decrease in species diversity were "recreation activities," "forest management," "environmental pollution," and "habitat loss" (Table 5). Although statistical 
(A)

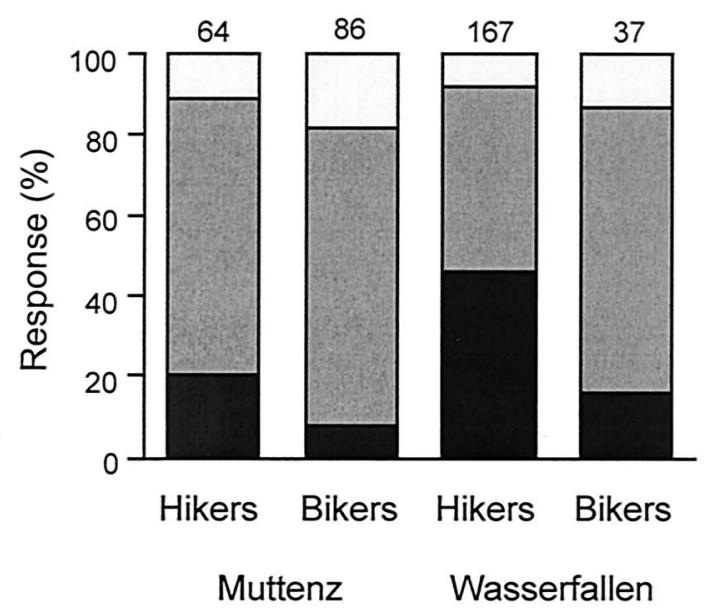

(B)

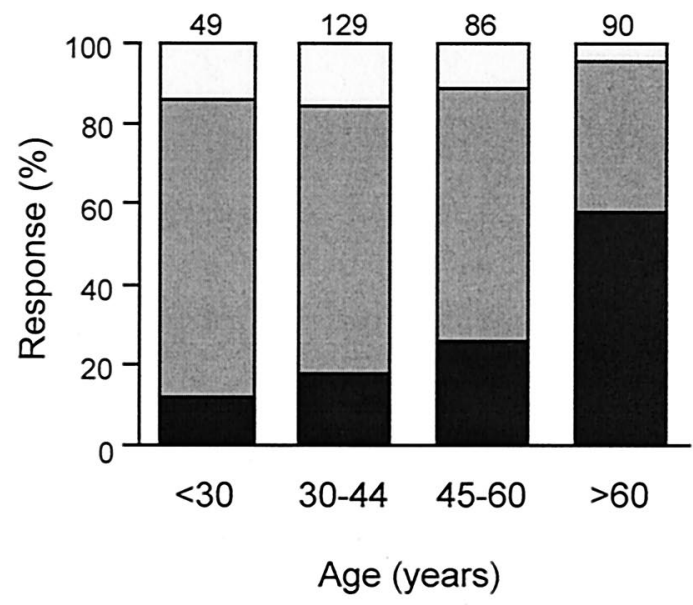

\section{Natural $\quad \square$ Semi-natural $\square$ Cultivated}

Figure 4. Assessment $(\%)$ of the naturalness of the forest structure and tree composition (A) by hikers and mountain bikers in the two forests, Muttenz and Wasserfallen, and influence of interviewees' age on the assessment of the natural- ness of the forest structure and tree composition (B). In (B) data from both visitor groups and forests are combined. Numbers on top of columns indicate sample sizes.

Table 3. Knowledge on forest functions ${ }^{a}$

\begin{tabular}{|c|c|c|c|c|}
\hline \multirow[b]{2}{*}{ Forest functions } & \multicolumn{2}{|c|}{ Muttenz } & \multicolumn{2}{|c|}{ Wasserfallen } \\
\hline & $\begin{array}{l}\text { Hikers } \\
\text { Freq. (\%) }\end{array}$ & $\begin{array}{l}\text { Mountain bikers } \\
\text { Freq. (\%) }\end{array}$ & $\begin{array}{l}\text { Hikers } \\
\text { Freq. (\%) }\end{array}$ & $\begin{array}{c}\text { Mountain bikers } \\
\text { Freq. (\%) }\end{array}$ \\
\hline Air/oxygen production & $43(33.6)$ & $56(28.0)$ & $131(35.0)$ & 28(33.0) \\
\hline Recreation & $34(26.6)$ & $54(27.0)$ & $74(19.8)$ & $18(21.2)$ \\
\hline Habitat for plants and animals & $15(11.7)$ & $34(17.0)$ & $46(12.3)$ & $13(15.3)$ \\
\hline Other ecological functions & $9(7.0)$ & $16(8.0)$ & $17(4.6)$ & $8(9.4)$ \\
\hline Water purification/retention & $3(2.3)$ & $5(2.5)$ & $28(7.5)$ & $3(3.5)$ \\
\hline Climate regulation & $7(5.5)$ & $11(5.5)$ & $24(6.4)$ & $3(3.5)$ \\
\hline Economic function (timber) & $5(3.9)$ & $7(3.5)$ & $8(2.1)$ & $1(1.2)$ \\
\hline Protective functions (erosion etc.) & $8(6.3)$ & $11(5.5)$ & $25(6.7)$ & $4(4.7)$ \\
\hline Other functions & $4(3.1)$ & $6(3.0)$ & $21(5.6)$ & $7(8.2)$ \\
\hline Total & 128 & 200 & 374 & 85 \\
\hline
\end{tabular}

${ }^{\mathrm{a}}$ Hikers and mountain bikers were interviewed in two forests (Muttenz and Wasserfallen) in northwestern Switzerland. Multiple responses were possible.

analysis revealed an influence of age on the reasons the interviewees thought responsible for a decrease in species diversity $\left(\chi^{2}=13.01, d f=6, P=0.043\right)$, no clear age-dependent pattern could be detected. However, interviewees younger than 30 years most frequently mentioned "global change" and "hunting" as causes for a decrease in species diversity. As reasons for a pre- sumed increase in species diversity, the forest visitors interviewed mentioned "nature conservation," "forest management," and "general environmental care" (Table 5).

Nearly all interviewed hikers and mountain bikers could name at least one plant or animal species more or less typical of the type of forest they visited. The most 
(A)

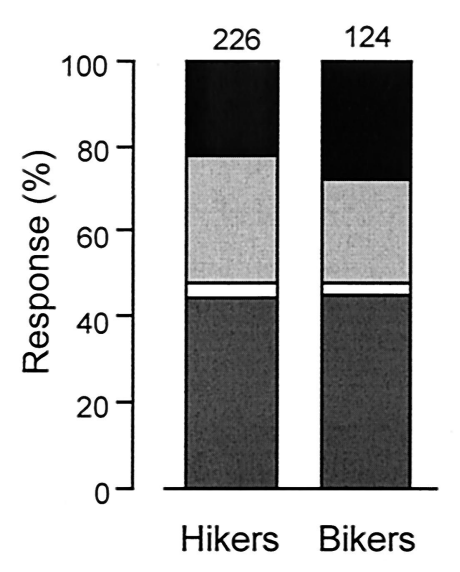

(B)

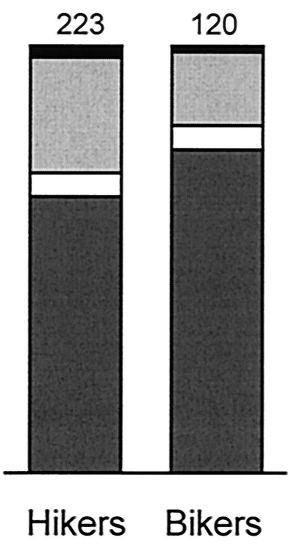

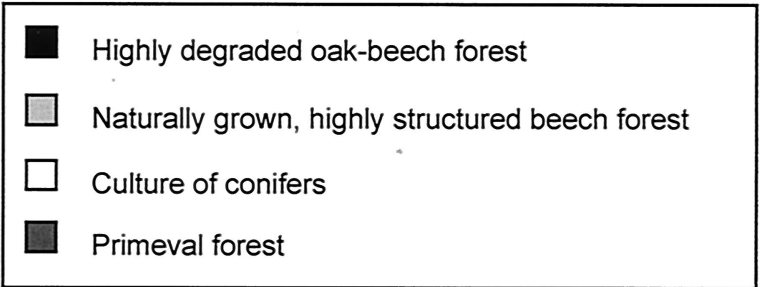

Figure 5. Preference of hikers and mountain bikers (\%) for a particular forest type with respect to recreational activity (A), and their assessment $(\%)$ of the benefit of different forest types for plants and animals (B). Data from both forests are combined. Numbers on top of columns indicate sample sizes.

Table 4. Reasons for forest protection mentioned by hikers and mountain bikers ${ }^{a}$

\begin{tabular}{|c|c|c|c|c|}
\hline \multirow[b]{2}{*}{ Reason for forest protection } & \multicolumn{2}{|c|}{ Muttenz } & \multicolumn{2}{|c|}{ Wasserfallen } \\
\hline & $\begin{array}{l}\text { Hikers } \\
\text { Freq. (\%) }\end{array}$ & $\begin{array}{c}\text { Mountain bikers } \\
\text { Freq. (\%) }\end{array}$ & $\begin{array}{l}\text { Hikers } \\
\text { Freq. (\%) }\end{array}$ & $\begin{array}{c}\text { Mountain bikers } \\
\text { Freq. }(\%)\end{array}$ \\
\hline Protection of animals & $37(32.8)$ & $57(37.0)$ & $86(31.1)$ & $17(27.9)$ \\
\hline Preservation of plants (forest floor) & $30(26.6)$ & $52(33.8)$ & $75(27.1)$ & $20(32.8)$ \\
\hline Undisturbed development & $18(15.9)$ & $29(18.8)$ & $59(21.3)$ & $13(21.3)$ \\
\hline Preservation of forest (area, functions) & $11(9.7)$ & $5(3.3)$ & $28(10.1)$ & $5(8.2)$ \\
\hline Protection from forest visitors & $7(6.2)$ & $3(1.9)$ & $8(2.9)$ & $2(3.3)$ \\
\hline Scientific experiment & $4(3.5)$ & $3(1.9)$ & $12(4.3)$ & $3(4.9)$ \\
\hline Other & $6(5.3)$ & $5(3.3)$ & $9(3.2)$ & $1(1.6)$ \\
\hline Total & 113 & 154 & 277 & 61 \\
\hline
\end{tabular}

${ }^{a}$ The interviews were conducted in two forests (Muttenz and Wasserfallen) in northwestern Switzerland. Multiple responses were possible.

frequently named species belonged to the organism groups "trees" (47\%), "vertebrates, excluding birds" $(33 \%)$, and "birds" $(11 \%)$. "Plant" $(4 \%)$ and "invertebrate" $(6 \%)$ species were less frequently mentioned. Responses were influenced by the interviewees' age $\left(\chi^{2}\right.$ $=19.14, d f=6, P=0.004)$. With increasing age tree species were more frequently mentioned, while younger interviewees slightly more often named vertebrate or bird species.

Sixty-five percent of the interviewed hikers and mountain bikers could correctly name at least three of the four tree leaves presented. Although the number of correctly determined leaves was significantly linked to the level of education $\left(\chi^{2}=15.55, d f=8, P=0.049\right)$, no clear tendency could be observed. While beech, oak, and maple were recognized by about $80 \%$ of the interviewees, only $30 \%$ could correctly name leaves of an ash tree.

\section{Discussion}

\section{Characteristics of Hikers and Mountain Bikers}

In the present study, hikers and mountain bikers differed in demographic parameters (gender ratio, age, and education), and in some aspects of forest visit behavior. Furthermore, the forest visit behavior differed between the two forests examined. At Muttenz, hikers and mountain bikers visited the forest more frequently, came in smaller groups, and traveled shorter distances to reach the forest (primarily by bike, foot, or public transportation) than at Wasserfallen. This confirmed the presumed differences in the recreational use of the two areas as recreation forest (Muttenz) and excursion forest (Wasserfallen). Generally, forest visit behavior appears to be affected by the remoteness of an area. Similarly, Volk (1992) found in more distant forests in Germany a larger proportion of 
Table 5. Reasons for presumed decrease/increase in species diversity mentioned by hikers and mountain bikers ${ }^{\mathrm{a}}$

\begin{tabular}{|c|c|c|c|c|}
\hline & \multicolumn{2}{|c|}{ Muttenz } & \multicolumn{2}{|c|}{ Wasserfallen } \\
\hline & $\begin{array}{l}\text { Hikers } \\
\text { Freq. (\%) }\end{array}$ & $\begin{array}{c}\text { Mountain bikers } \\
\text { Freq. }(\%)\end{array}$ & $\begin{array}{c}\text { Hikers } \\
\text { Freq. (\%) }\end{array}$ & $\begin{array}{c}\text { Mountain bikers } \\
\text { Freq. }(\%)\end{array}$ \\
\hline \multicolumn{5}{|c|}{ Reasons for decrease in species diversity } \\
\hline Forest management & $7(11.5)$ & $28(27.7)$ & $40(26.1)$ & $12(34.3)$ \\
\hline Recreation activities & $25(41.0)$ & $29(28.7)$ & $31(20.3)$ & $9(25.7)$ \\
\hline Environmental pollution & $11(18.0)$ & $21(20.8)$ & $38(24.8)$ & $9(25.7)$ \\
\hline Habitat loss & $14(23.0)$ & $15(14.8)$ & $30(19.6)$ & $4(11.4)$ \\
\hline Hunting & $1(1.6)$ & $1(1.0)$ & $3(2.0)$ & $1(2.9)$ \\
\hline Global change & $1(1.6)$ & $3(3.0)$ & $4(2.6)$ & $0(0.0)$ \\
\hline Other & $2(3.3)$ & $4(4.0)$ & $7(4.6)$ & $0(0.0)$ \\
\hline Total & 61 & 101 & 153 & 35 \\
\hline \multicolumn{5}{|c|}{ Reasons for increase in species diversity } \\
\hline Nature conservation & $2(28.6)$ & $3(60.0)$ & $10(43.5)$ & $0 \quad(0.0)$ \\
\hline Forest management & $4(57.1)$ & $1(20.0)$ & $3(13.1)$ & $1(33.3)$ \\
\hline General environmental care & $0(0.0)$ & $1(20.0)$ & $5(21.7)$ & $2(66.7)$ \\
\hline Other & $1(14.3)$ & $0(0.0)$ & $5(21.7)$ & $0(0.0)$ \\
\hline Total & 7 & 5 & 23 & 3 \\
\hline
\end{tabular}

aThe interviews were conducted in two forests (Muttenz and Wasserfallen) in northwestern Switzerland. Multiple responses were possible.

visitors that rarely went to the forest, but a higher frequency of people that stayed longer in the forest.

\section{How Do Hikers and Mountain Bikers Perceive Prevailing Forest Conditions?}

The interviewees' responses regarding positive and negative experiences with other forest visitors clearly reflect the different situations prevailing in the forests at Muttenz and Wasserfallen. Muttenz is a very popular destination for mountain bikers. They come to Wasserfallen much less frequently. Mountain bikers are one of the most problematic forest visitor groups in frequently visited forests, particularly if they occur in large numbers (Baur 1999; BUWAL 1999; Kleiber 2001). Accordingly, at Muttenz a large number of hikers mentioned negative encounters with other forest visitors, especially with mountain bikers due to their high speed, lack of courtesy, crowding, or safety concerns.

In most cases, conflict attribution between hikers and mountain bikers is asymmetric (Ramthun 1995). Correspondingly and in contrast to hikers, mountain bikers of the present survey appreciated neutral or even positive encounters with other forest visitors, i.e., with hikers that stood aside to enable them to pass each other on narrow trails or that greeted them in a friendly way. Thus, we assume that at least some of the mountain bikers are aware of the possible conflicts between their activity and other forms of recreation in the forest.

Positive remarks on the state of the forest were less frequently made by mountain bikers than by hikers. This suggests that mountain bikers not only have an enhanced awareness of possible social conflicts (as shown above), but most probably recognize the impact of their activity on the forest floor or on paths and trails. In a survey conducted in the United States, the United Kingdom, Australia, and New Zealand, $42 \%$ of mountain bikers perceived their activity as having a medium level of impact on trails, while $39 \%$ rated the level as low, and only $18 \%$ thought that the impact was high (Symmonds and Hammitt 2000). In the same study, $91 \%$ of mountain bikers assumed that their activity causes some degree of trail erosion, but only $10 \%$ stated that mountain biking "greatly" accelerated trail erosion.

Although in our survey mountain bikers did not make negative comments on the conditions of paths/ trails or perceptions of forest damage with a higher frequency than hikers, they generally assessed the forest state less optimistically. Especially at Muttenz, mountain bikers considered recreational activities as having a more pronounced impact on the forest state than hikers did. A higher percentage of mountain bikers perceived "damage to forest floor/vegetation" and assessed the forest only as "seminatural" or even as "cultivated." Therefore, we conclude that mountain bikers might indeed have an enhanced awareness of the possible impacts of mountain biking on the forest state.

The fact that the interviewees (hikers and mountain bikers) at the two forests differed in their responses in three of the five questions concerning the perception and knowledge of the state of the forest indicates that they might actually perceive the prevailing condition of the forest they visit. Baur (1999) reported that forest visitors' assessment of forest damages caused by recre- 
ational activities varies among differently affected areas. Similarly, Kleiber (2001) found that forest visitors recognize the recreational overusage of the visited forest.

The interviewees' gender and age were most influential on how the conditions in the forest were perceived and assessed. Women seem to be more attentive while traveling through the forest, since they more frequently reported positive perceptions as well as damages to the forest. Furthermore, members of environmental organizations had an enhanced awareness of forest damage. Similarly, Gasser (1994) found that people visiting the forest to observe nature are more aware of forest damage than hikers, joggers, or mountain bikers. However, in our study the kind of perceived forest damage was significantly influenced by the interviewee's age. "Diseased/infested trees" were less often mentioned by younger hikers and mountain bikers $(<$ 44 years). This is probably due to the fact that younger people were not involved in the debate on the "Waldsterben" (dying of forests) in Switzerland 20 years ago. The older visitors might still be sensitized and thus have an enhanced awareness of this kind of forest damage. In a Swiss nationwide survey the interviewees' age had also a significant influence on the assessment of the forest state (BUWAL 1999).

Forest Functions and Species Diversity: What Do Hikers and Mountain Bikers Know and Perceive?

Only a minority of the interviewed hikers and mountain bikers was aware of the economic (timber production) and protective (erosion, avalanches, etc.) function of the forest. For the most part, the interviewees thought of the forest as a place for recreation, but also with ecological functions, in particular the production of clean air and oxygen. This result confirms earlier findings, in which forests were perceived as spaces for recreational activities and relaxation, but also as places for the production of clean air (Schmithüsen and WildEck 2000), and in which the economic function of the forest was considerably underestimated (Fröhlich and Klingelhöfer 1977; Hertig 1979; Gasser 1994). This indicates that hikers and mountain bikers attribute a high value to the recreational function of the forest.

A large proportion of the interviewed hikers and mountain bikers correctly mentioned one or several reasons for decreases in plant and animal species diversity and knew why areas of a forest might have to be protected. Nearly all of them could name some forest plant and/or animal species and recognized at least three of the four common forest tree leaves presented. In addition, a majority correctly considered the "primeval forest" as the most suitable habitat for many plants and animals. Thus, most interviewees had a rather good ecological or biological forest knowledge. They seemed to be aware of the pros and cons of different forest conditions for plants and animals. For instance, although $25 \%$ of the interviewees preferred the "highly degraded oak-beech forest" for their recreational activity, only $7 \%$ thought that this forest type was the best habitat for plants and animals. This result contradicts earlier findings, where a lack of knowledge of forest and nature concerns among the population (BUWAL 1999), as well as a low familiarity with natural processes and the many functions of the forests, especially among urban dwellers, was reported (Konijnendijk and others 2000). However, besides some differences in the precise aspects of forest knowledge examined, there are also some methodological differences between these studies, e.g., the BUWAL (1999) study was a nationwide telephone survey.

Papageorgiou (2001), who examined national parkrelated knowledge in Greece, found a discrepancy between general and more specialized environmental knowledge. For instance, a very high percentage of the park users was familiar with the term "national park," but only a small number knew more about the national park concept. In the present survey, the familiarity with terms such as Artenvielfalt (species richness) was relatively high. Moreover, the interviewees subsequently provided additional knowledge on the subject by correctly stating possible reasons for a decrease or increase in species diversity.

Interestingly, neither the type of recreational activity carried out, nor any aspect of forest visit behavior had a distinct influence on forest knowledge and perception. In other words, hikers and mountain bikers that frequently visited the forest, those that stayed longer in the forest, or those that traveled long distances to reach the forest did not know more about the forest (i.e., its functions and species diversity) than the other hikers and mountain bikers. However, one is tempted to assume that more highly educated hikers and mountain bikers as well as members of environmental organizations should have better ecological or biological forest knowledge. Indeed, the familiarity with the term Biodiversität (biodiversity) increased with an increasing level of education and was higher among members of environmental organizations. However, no other aspect examined of ecological/biological forest knowledge was influenced by level of education or by membership in environmental organizations (at least not in a clear way). Instead, knowledge of forest species (organism groups) depended on the interviewees' age. Interestingly, the preferred forest type for recreation was influenced by the level of education but not the assessment of the benefit of different forest types for plants and 
animals. Contrary to this, an earlier study on visitors' preferred forest type in terms of structure and composition had not revealed a significant correlation with education (Rozsnyay 1979). Papageorgiou (2001) found similar relationships between environmental knowledge and sociodemographic variables as in the present study: age proved to be the major knowledge determinant, while educational level was only of limited influence, and gender had no effect at all.

Lindhagen and Hörsten (2000) stated that the importance of biodiversity has become part of the public consciousness during the last decades. They found a higher valuation of "virgin forests" in Sweden in 1997 compared to 1977 . This was particularly true for the youngest respondents of the survey and was explained by a faster adoption of new ideas among the young. In our study, we also found some discrepancies in the awareness and valuation of a "natural forest" between younger and older hikers and mountain bikers. The percentage of interviewees that considered the "highly degraded oak-beech forest" as the most suitable habitat for plants and animals was largest in the age class $>$ 60 years. At the same time, members of this age class chose the "primeval forest" as the best habitat for plants and animals with the smallest frequency of all age classes. Furthermore, they assessed the forest they visited clearly as more natural than all the others did, and more frequently considered "dead/fallen trees" as forest damage. Similarly, Tahvanainen and others (2001) found attitudes towards forests in natural states to be more positive among younger persons.

\section{Conclusions and Management Implications}

The results of this survey showed different perceptions of the prevailing conditions in the forest between hikers and mountain bikers and different forests. Mountain bikers in both forests examined and hikers in the more intensely used forest at Muttenz had a higher awareness of the consequences of recreational activities in the forest (social conflicts and ecological impacts) than hikers in the forest at Wasserfallen. However, no such distinctions were found for the forest knowledge of the interviewed hikers and mountain bikers (forest functions and types, aspects of species diversity). The interviewees' age was most influential on forest perception and knowledge. To a lesser extent gender, education, and membership in an environmental organization were linked to forest perception and/or knowledge. Contrary to this, aspects of forest visit behavior (frequency and duration of forest visits, distance to the forest) had hardly any effect on the perception and knowledge of the forest.
Although many of the interviewed hikers and mountain bikers perceived the conditions prevailing in the intensely visited forest, and generally a large proportion had a rather good biological forest knowledge, social conflicts and forest damage due to recreational activities still occur at Muttenz. Obviously, awareness and knowledge do not necessarily result in a change of behavior, and a portion of the hikers and mountain bikers was still unaware of the consequences of their recreational activities. Thus, further management practices to educate and manage different forest visitor groups are required.

Former studies have shown that information on the reasons of forest management practices can lead to a higher acceptance among forest visitors (Brunson and Reiter 1996; Hunziker 1997; Heer and others 2003). This is especially true if some activities have to be forbidden or the freedom of movement in the forest is restricted, as might be the case when protecting a part of a forest (e.g., to allow regeneration) or when actions are taken to prevent social conflicts (e.g., by directing different visitor groups onto different trails). As a consequence of the different perceptions of the prevailing forest conditions, adequate information tailored more directly to different forest visitor groups might help to further increase acceptance of forest management practices.

\section{Acknowledgments}

This work was supported by a grant of the MGU (Mensch-Gesellschaft-Umwelt) foundation of Basel University. We thank Georg Armbruster, William E. Hammitt, Samuel Zschokke, and two anonymous reviewers for helpful comments on the manuscript.

\section{Literature Cited}

Baudepartement Kanton Aargau and Landratsamt Waldshut (eds). 1999. Rheinlandschaft: Eine gemeinsame Strategie für Natur, Landschaft und Erholung. Teilbericht Besucherbefragung im Perimeter., 83 pp.

Baur, B. (ed.). 1999. Der Allschwiler Wald. Allschwiler Schriften zur Geschichte, Kultur und Wirtschaft. Band 11. Verkehrs- und Kulturverein, Allschwil, 154 pp.

Brunson, M. W., and D. K. Reiter. 1996. Effects of ecological information on judgments about scenic impacts of timber harvest. Journal of Environmental Management 46:31-41.

Bultena, G. L., D. Field, P. Womble, and D. Albrecht. 1981. Closing the gates: a study of backcountry use limitation at Mount McKinley National Park. Leisure Sciences 4:249-267.

Burnand, J., and B. Hasspacher. 1999. Waldstandorte beider Basel: Kommentar zur vegetationskundlichen Standortskartierung der Wälder. Verlag des Kantons BaselLandschaft, Liestal 266. 
BUWAL (ed.). 1999. Gesellschaftliche Ansprüche an den Schweizer Wald-Meinungsumfrage. Schriftenreihe Umwelt, No. 309, 152 pp.

Ditton, R. B., A. J. Fedler, and A. R. Graefe. 1983. Factors contributing to perceptions of recreation crowding. Leisure Sciences 5:273-286.

Fröhlich, H. J., and H. Klingelhöfer. 1977. Ergebnisse forstlicher Öffentlichkeitsarbeit und Folgerungen aus einer Meinungsumfrage in Hessen. Allgemeine Forstzeitschrift 32:487-490.

Gasser, G. 1994. Aktivitäten der städtischen Forstverwaltung Liestal in der Wahrnehmung von Waldbesucherinnen und Waldbesuchern. Diplomarbeit, Professur für Forstpolitik und Forstökonomie, ETH Zürich, Arbeitsberichte Allgemeine Reihe, No. 97/1, 76 pp.

Heer, C., H. P. Rusterholz, and B. Baur. 2003. Information und Akzeptanz von Pflegemassnahmen bei Besuchern eines stadtnahen Erholungswaldes. Wald und Holz 2:36-39.

Hertig, H. P. 1979. Die Einstellung der Bevölkerung zu Problemen des Waldes und der Waldwirtschaft. Ergebnisse einer Meinungsumfrage. Schweizerische Zeitschrift für Forstwesen 130:591-611.

Hoger, J. L., and D. J. Chavez. 1998. Conflict and management tactics on the trail. Parks and Recreation 33:41-56.

Hunziker, M. 1997. Totholz in den Nationalparkwäldern: Attraktion oder Störfaktor? Ergebnisse einer sozialwissenschaftlichen Studie. Cratschla 2:2-8.

Jacsman, J. 1998. Konsequenzen der intensiven Erholungsnutzung für die Wälder im städtischen Raum. Schweizerische Zeitschrift für Forstwesen 149:423-439.

Kleiber, O. 2001. Valuation of recreational benefits and visitor conflicts in an urban forest. Fifth International Conference of the International Society for Ecological Economics (ISEE), Moscow, Russia, 15 pp.

Konijnendijk, C. C. 2000. Adapting forestry to urban demands-role of communication in urban forestry in Europe. Landscape and Urban Planing 52:89-100.

Lamprecht, M., and H. Stamm. 1994. Die soziale Ordnung der Freizeit: Soziale Unterschiede im Freizeitverhalten der Schweizer Wohnbevölkerung. Seismo, Zürich, 564 pp.

Lindhagen, A., and L. Hörnsten. 2000. Forest recreation in
1977 and 1997 in Sweden: Changes in public preferences and behaviour. Forestry 73:143-153.

Martin, S. R., S. F. McCool, and R. C. Lucas. 1989. Wilderness campsite impacts: do managers and visitors see them the same? Environmental Management 13:623-629.

Moore, R. L. 1994. Conflicts on multiple-use trails: synthesis of the literature and state of the practice. The Federal Highway Administration and the National Recreational Trails Advisory Committee, Federal Highway Administration, US Department of Transportation, $68 \mathrm{pp}$.

Papageorgiou, K. 2001. A combined park management framework based on regulatory and behavioral strategies: uses of visitors' knowledge to assess effectiveness. Environmental Management 28:61-73.

Ramthun, R. 1995. Factors in user group conflict between hikers and mountain bikers. Leisure Sciences 17:159-169.

Rozsnyay, Z. 1979. Zum Mischwaldbegriff der Waldbesucher und ihre Ansichten über die Schichtigkeit der BeständeErgebnisse einer Meinungsumfrage in Königsforst bei Köln. Forstwissenschaftliches Centralblatt 98:222-233.

Schmithüsen, F., and S. Wild-Eck. 2000. Uses and perceptions of forests by people living in urban areas-findings from selected empirical studies. Forstwissenschaftliches Centralblatt 119:395-408.

Symmonds, M. C., and W. E. Hammitt. 2000. Managing recreational trail environments for mountain bike user preferences. Environmental Management 25:549-564.

Tahvanainen, L., L. Tyrväinen, M. Ihalainen, N. Vuorela, and O. Kolehmainen. 2001. Forest management and public perceptions-visual versus verbal information. Landscape and Urban Planing 53:53-70.

Volk, H. 1992. Neue Entwicklungen bei der Walderholung in Südwestdeutschland. Forstwissenschaftliches Centralblatt 111:282-292.

West, P. C. 1982. Effects of user behaviour on the perception of crowding in backcountry forest recreation. Forest Science 28:95-105.

Womble, P., D. Johnson, G. Bultena, and D. Field. 1980. The response of hikers to seeing resource impacts in the backcountry. Final report submitted to USDI National Park Service, in cooperation with the Cooperative Park Studies Unit, College of Forest Resources. University of Washington, Seattle 17 . 